\title{
Racismo, subalternización política y derechos negados en América Latina
}

\author{
Racism, political subordination and denied rights in Latin America \\ Alejandro Tomás ${ }^{1}$ y Hernán Dal Molin ${ }^{2}$
}

\section{Resumen}

En el presente trabajo nos proponemos realizar un análisis respecto al recorrido del Racismo en América Latina. Para ello nos adentraremos en sus causas, su evolución, aquellos factores que han sido determinantes para que perdure en el tiempo y si los Estados han tomado -o no- medidas para limitar estas prácticas. A su vez, haremos hincapié en aquellas medidas que persisten en la actualidad, distinguiendo aquellos casos que se dan en el ámbito político y cómo éstos han afectado la vida de ciertos sujetos en cuanto al reconocimiento y ejercicio efectivo de sus derechos fundamentales.

\section{Palabras clave: Racismo, Discriminación, América Latina}

\section{Abstract}

The present study is willing to perform an analysis about the trajectory that Racism has had in Latin America. For this purpose, we will take a closer look to its grounds, its evolution, those factors that had been crucial for its continuance over the passing of time, and also examine if the different states have taken - or not- actions to restrict these practices. Moreover, we will focus on those measures that still persist at the present time, discriminating the cases that occur in the political sphere and how these have affected the life of a number of individuals regarding the recognition and full exercise of their fundamental rights.

Keywords: Racism, Discrimination, Latin America

\section{Introducción}

Las genealogías del racismo son un fenómeno que datan desde los albores de la Modernidad. Concretamente, desde el encuentro con el no-europeo. La noción de "raza" toma su significado para el europeo, durante la Conquista, en suelo americano

\footnotetext{
Recibido: 25 de marzo de 2021 Aceptado: 16 de junio de 2021 Publicado: 8 de julio de 2021

${ }^{1}$ Estudiante de Derecho. Universidad Nacional de Rosario (UNR), Rosario, Argentina. Correo electrónico: aletomas95@gmail.com ID https://orcid.org/0000-0003-1636-8689

2 Estudiante de Música. Universidad Nacional de Rosario (UNR), Rosario, Argentina. Correo electrónico: hernandalmolin@gmail.com ID https://orcid.org/0000-0001-9356-6940
} 
(Quijano, 2011, p. 5). Es el germen desde donde surge (y se construye) la concepción de una alteridad, de unx "otrx", a través de su apreciación fenotípica. En ese sentido "el racismo es la consecuencia de la lectura, en los cuerpos, de la historia de un pueblo. Es la lectura (...) y la atribución automática, prejuiciosa, de características intelectuales y morales que, de alguna forma, son inherentes a esos cuerpos" (Segato, 2012, p. 6). El cuerpo que constituyó el ideal de la Modernidad era el de hombre y blanco, toda figura humana que escapara a esas dos cualidades obtendría, en el más leve de los casos, una sentencia de extrañeza ante los ojos del colonizador.

Si bien describimos que el racismo como tal fue de los primeros rasgos que se le atribuyen a los comienzos de la época moderna, sólo a partir de los siglos XVIII y XIX fue cuando empezó a tomar consideración como teoría científica con Joseph Arthur de Gobineau como más claro referente. Dichos preceptos fueron recogidos más tarde en el siglo XX por los movimientos nazis/fascistas.

A lo largo de la historia mundial, el odio racista ha funcionado como un medio estructurador de encajes políticos, un justificador, el chivo expiatorio para llevar adelante políticas de exclusividad para distintos sectores e incluso en la actualidad sigue siendo un factor de desigualdad social muy marcado, sobre todo en nuestra región "los pueblos indígenas de las Américas denuncian la opresión y discriminación de las cuales siguen siendo objeto, así como su persistente pobreza en medio de la abundancia" (Stavenhagen, 1993, p. 9).

Entendemos al racismo como un conjunto de actos, actitudes, formas de expresarnos a partir de ciertos conceptos preestablecidos que heredamos a partir de una concepción que tiene su origen en los inicios de -como ya explicamos anteriormente- el fenómeno del colonialismo originario, la conquista. No queremos dejar de señalar que el racismo en tanto conjunto de prácticas y de ethos nace desde un único vientre: el de la violencia.

Desde la conquista, podemos atisbar que -con sus diferentes matices a lo largo de la historia- no siempre decidimos por nosotros mismos, que hay factores externos que influyen en la política -sobre todo- latinoamericana, y adyacente a la misma, muchas decisiones sociales y económicas que han llegado a producir diferentes efectos sobre nuestras poblaciones.

Hoy en día, esos factores siguen presentes, pero de diferentes formas. El colonialismo se va reinventando, por eso

en esta $<<$ fase superior del colonialismo $>>$ no se ocupan territorios policialmente, como en el colonialismo originario, derrotado por los libertadores; tampoco se acude a oligarquías vernáculas que mantengan a la población en servidumbre, como las que los pueblos desplazaron hace un siglo; ni siquiera se psicotiza a las fuerzas armadas para que ocupen los 
territorios por cuya soberanía debían velar, porque ya no son confiables y provocan resistencia popular (Zaffaroni, 2015, p. 47).

Como habrá podido observar el lector, identificamos al Colonialismo -en su función de segregación y jerarquización- como uno de los factores promotores del racismo en nuestra región. No es el único, el capitalismo, la modernidad, la globalización, contribuyen a la réplica y naturalización de prácticas racistas que muchas veces inciden en el ejercicio de derechos fundamentales de las personas.

Consideramos los factores anteriores como interdependientes. Si bien no necesariamente surgen como consecuencia uno del otro, entendemos que dentro de sus características propias y de su relación en distintos ámbitos dentro de los cuales se manifiestan, influyen en la construcción del fenómeno desarrollado en el presente trabajo. Si bien existe cierta autonomía en cada uno, dichos factores establecen una dialéctica entre ellos en la cual se va configurando la trama del racismo en tanto fenómeno socio-cultural. Dicho diálogo se explica en el sentido de que para comprender cabalmente el fenómeno racial es preciso considerar las distintas instancias de una sociedad (lo político, lo económico, lo jurídico y lo cultural), y ser conscientes de que cada una influye.

El racismo es parte integrante de todas las formas de explotación. Por eso el capitalismo establece jerarquías raciales y depende de ellas para profundizar la expropiación de la que se beneficia" (Borges); la simple observación de las diferentes labores que realizan las personas nos permite distinguir ciertos estratos racistas reforzados por el capitalismo, inmigrantes, afrodescendientes, personas LGBTIQ+ - entre otros-, se ven dificultados de integrarse en un mercado laboral justo, condenándolos de esta forma a la precarización laboral que les impide abastecerse de los recursos económicos necesarios para satisfacer sus necesidades fundamentales. "En Brasil, los negros ocupan los puestos de trabajo de menor prestigio, y habitan largamente el lugar de los que no tienen nada, a pesar de los cambios significativos de las últimas décadas (Borges).

"La globalización es un proceso de integración que tiende a crear un solo mercado mundial en el que se comercian productos semejantes, producidos por empresas cuyo origen es difícil de determinar, ya que sus operaciones se distribuyen en varios países" (Kozikowski, 2007, p. 6). Pensemos en el desplazamiento poblacional generalizado que se produce a causa de esta manifestación mundial, gente de todo el mundo emigrando de sus países en busca -y con promesas- de nuevas oportunidades.

Ya no hablamos de colonialismo originario, pero visualizamos una cotidiana y constante situación de encuentro con "lx otrx", que es un factor influyente en las 
relaciones sociales entre las personas y que termina afianzando la idea de racismo. ¿O acaso nunca escuchamos a nadie referirse a una persona llamándola por su nacionalidad de una forma despectiva? Si nos ponemos a pensar en cuántas veces vemos esto, nos asustaríamos de nuestro propio racismo, el de las personas que nos rodean y del que se produce por parte de las instituciones estatales.

A su vez, el concepto de subalternidad, heredado de la teoría gramsciana, resulta necesario para comprender las lógicas raciales ya que lo subalterno denota, en esencia, los trazos de una subjetividad. Desde esta perspectiva, "la subalternidad es pensada como una condición ontológica en relación a contextos históricos predeterminados” (Rodríguez, 1998, p. 85). Lo subalterno se piensa como receptáculo de las desigualdades, se inscribe en una posición. Desde el lado de su contraparte, la hegemonía, es donde dentro de la propia sociedad se produce "una narrativa historicista de $<<$ desarrollo $>>$ que, a causa de sus prerrequisitos culturales y legales (...) excluye a amplios sectores de la población de la ciudadanía o limita su acceso a ella” (Beverley, 2010, p. 24). ¿Cómo no pensar en estos términos cuando a simple vista es tan clara la falta de derechos (políticos, culturales, económicos y sociales) y oportunidades en vastos sectores de nuestras sociedades?

Como ya hemos planteado, consideramos que nos encontramos en conformidad con un sistema y con factores externos que hacen sensibles a nuestras democracias de llevar adelante o naturalizar accionares que podrían encajar en este tipo de conductas. Ya que en el presente no estamos ajenos a esto, corresponde -en esta introducción- definir qué entendemos al hablar de esta problemática. Nos referiremos al racismo -entre todas sus formas- en base a lo establecido por la Convención Internacional para la Eliminación de todas las formas de Discriminación Racial (CERD), quien la define como

cualquier distinción, exclusión, restricción o preferencia basada en la raza, color, descendencia u origen nacional o étnica que tenga el propósito o el efecto de anular o perjudicar el reconocimiento, gozo o ejercicio en pie de igualdad de los derechos humanos y de las libertades fundamentales.

Si bien entendemos al racismo como un fenómeno que se produce en todo el mundo, en las siguientes líneas desarrollaremos cuestiones referidas a la temática poniendo el eje en nuestra América Latina. Factores que contribuyen a que se lleven a cabo éstas prácticas, la naturalización y reiteración por parte de la ciudadanía, aquellos casos en los que el propio Estado retroalimenta dichos accionares produciendo una vulneración en algún derecho fundamental y qué desafíos tenemos por delante para lograr políticas públicas ciudadanas cuya finalidad sea impulsar proyectos de vida que se encuentren ajenos a todos aquellos actos que podemos considerar -tomando como referencia la definición del párrafo anterior- racistas. 


\section{El papel del Estado}

La formación de los Estados modernos -entendidos como procesos históricos, pero también como racionalidad gubernamental- supuso la configuración de un dispositivo que lograra cohesionar en algún sentido a lxs sujetos que habitaban un mismo suelo. Es así que se erigió como constructo socio-cultural, político y simbólico la idea de una identidad nacional cerrada y unívoca. Ahora bien, la configuración de dicha identidad implicó en realidad un recorte y una selección de atributos y características (físicas, morales, intelectuales, etc.) en detrimento de otras dentro del mismo suelo eliminando toda posibilidad de pluralismo. Es así como a la entronización de un "Nosotrxs" se le contrapone la emergencia de unx "Otrx". Es en ese sentido en el que Pombo habla de "identidades excluyentes" como

una forma de agregación social en la cual el "nosotros" aparece como una figura social fijada en el tiempo, en un sistema abstracto, indeterminado o mítico. El Otro, a la vez, no es percibido nunca como un actor real: es naturalizado, objetivado o bien asociado con un principio metasocial (el mal, la decadencia, el diablo...) (Pombo, 1999, p. 60).

La idea de nación en términos políticos/jurídicos es un concepto creado por la filosofía francesa en el siglo XVIII, dicha noción descansaba sobre tres máximas: "(1) una gran multitud de hombres, (2) habitando en un país determinado, delimitado por fronteras y (3) que obedecieran las mismas leyes y a un gobierno único" (Pombo,1999, p. 71). Dichas ideas fueron tomadas por los libertadores en América Latina durante los procesos revolucionarios, momento en el cual se establece un rechazo de la identidad colonial, si bien no todos los países lograron cesar el dominio colonial de la misma forma,

en el contexto de estas luchas existieron intentos mucho más avanzados de política nacionalista y anticolonial, como las del juarismo en México. Está también el caso de Cuba, que logra su independencia de España apenas en los albores del siglo XX, después de dos largas etapas de una encarnizada guerra, lucha que produce un líder de la talla de José Martí quien vincula, por vez primera en forma sistemática, el nacionalismo y el antimperialismo (Bambirra, 1975, p. 10).

Sin embargo, con el tiempo y con el objetivo de mantener y reproducir el ideal nacional y sobre todo con el temor a que éste se pierda, se comenzó a instaurar dentro de los propios Estados -con las elites a la cabeza- prácticas y discursos que atropellaban la integridad de aquellxs sujetos que estaban por fuera de los arquetipos de la nación. Es de esta forma como podemos ver inmersas en el cuerpo de los Estados las raíces del sentimiento racista. Para el siglo XIX, en América Latina, el discurso 
científico cala hondo en los sectores dirigenciales del Estado y es así como en el continente se llega a una "racionalidad racial" en el que algunas culturas son, "naturalmente", superiores a otras. En Argentina, Sarmiento, al imaginar lo que sería su república ideal, es el primero en introducir la noción de raza (Villavicencio, 2018, p. 191). El proceso se consolida entre los años 1880 y 1930, es en los albores del siglo $\mathrm{XX}$ en el que el Estado comienza un proceso de establecimientos de políticas que abogaban por una delimitación de la condición antropológica y simbólica de "lo nacional”, un "proyecto de argentinización" (Grimson, 2006, p. 2). Es así como, en consecuencia, ciertos sectores pasarían a ser objeto de constante vigilancia, entre ellxs indígenas y migrantes. De esta forma podemos observar que el racismo, en su extensa profundidad, careciendo de cualquier tipo de atributo que le otorgue un rasgo de novedad debe entenderse como una mácula histórica impregnada en nuestro tejido social.

La cuestión del nacionalismo, fenómeno que se desprende de la conciencia del Estado moderno como elemento interno a éste, es una idea de carácter bifronte. Por un lado, y en algunos casos, fue uno de los elementos que se manifestaron para lograr la emancipación de los pueblos frente a intereses foráneos. Pero también puede verse como aquella noción totalizadora que no concibe la posibilidad de una heterogeneidad identitaria en un mismo suelo. Esta acción por buscar "lo nacional" detenta -en algunos casos- un ejercicio de discriminación, de parcialidad y segregación. Un doble juego de inclusión/exclusión. Es bajo este tipo de características que desde el Estado se erige un racismo nacionalista (Pombo, 1999, p. 66). Racismo, Estado y nacionalismo comprenden una tríada que se retroalimenta en donde se pone en juego lo cultural, lo político y el territorio.

Otro de los conceptos que contenía el fenómeno racial dentro de los Estados ha sido lo que muchos intelectuales y cientistas sociales denominan como colonialismo interno. Si bien es una categoría que ha sido discutida a lo largo del tiempo, se considera aquí un concepto que ayuda a esclarecer algunas aristas. El concepto fue acuñado por el sociólogo Charles Wright Mills y puede entenderse como la reproducción de prácticas coloniales -de un cariz intercontinental- establecidas desde épocas de la conquista pero ahora desde adentro de un mismo territorio, es la instauración de las categorías "dominadores" y "dominados" ahora entre nativxs, es la negación, no reconocimiento o violación de derechos sociales, políticos, culturales y económicos por parte de un sector hacia otro generando, naturalmente, un escenario de desigualdades. La génesis de un neocolonialismo (González Casanova, 2006, p. 186). Si bien el concepto tomó fuerza como categoría analítica en Latinoamérica con los aportes de González Casanova, el colonialismo interno debe entenderse como un fenómeno que caracterizó a todos los Estados independientemente de su geografía. 
Por ejemplo, existen diferencias entre el colonialismo interno que sucede dentro de Gran Bretaña y el de Latinoamérica, en el primero los atropellos resultan de índole cultural y de estatus, mientras que en el segundo remiten más al caso de derechos civiles y libertades (Torres Guillén, 2017, p. 2). Ligado muchas veces a la relación que se estableció entre los sectores urbanos y los rurales, el colonialismo interno es una práctica que se realiza de arriba hacia abajo en la pirámide socio-económica, desde una élite hacia sectores más vulnerables.

En los últimos años, en América Latina, además del colonialismo interno se estableció un nuevo factor que ha servido de ladero, el neoliberalismo. Esta diada conjuró una perversa trama en la que la integridad social y económica de varios sectores (mayormente populares) de una misma población se veía profundamente damnificada a partir de las políticas emitidas por los sectores dominantes del Estado muchas veces en coparticipación con los intereses de sectores internacionales como podían ser desde otros Estados hasta empresas privadas, dejando ver así una mentalidad de corte colonialista. Como uno de los más crueles ejemplos está lo ocurrido en Perú durante el gobierno de Alberto Fujimori, en donde durante los años 1996 y 2000 se realizó un plan de planificación familiar y control poblacional que consistió en la esterilización de aproximadamente 300.000 personas mayormente de población in dígena (Serra, 2017, p. 32).

Más acá en el tiempo, en el año 2019 durante el gobierno de facto de Jeanine Añez (asociado al FMI en 2020) resulta el caso de la masacre de Sacaba y Senkata en donde manifestantes y cocaleros que marchaban en apoyo a Evo Morales fueron reprimidos por la policía y fuerzas armadas y al menos 9 personas resultaron asesinadas en manos de éstas (Moldiz, 2020, p. 110). Vemos así que procesos como el colonialismo y el neoliberalismo en realidad operan bajo mecanismos de la racialidad al advertir y darnos cuenta que las víctimas de dichos procesos resultan ser siempre las mismas (negrxs, indígenas, trabajadorxs, campesinxs, etc.) sin importar lugar o época.

Hoy en día resulta imposible imaginar una disociación entre sociedad y Estado que resulte convincente. El Estado es un ente que nos contiene y a la vez nos sobrepasa, su acción o su omisión -lo que haga o deje de hacer-condiciona nuestras vidas de alguna forma, a veces más a veces menos. Esta aseveración de "más/menos" remite a lo que Juan Carlos Monedero (2017), mencionando los aportes de Bob Jessop, llama la "selectividad estratégica" del Estado (p. 104). La selectividad estratégica se configura a partir

(...) del desigual acceso al Estado y las desiguales capacidades para resistir al Estado fuera de él; de la desigual capacidad para definir y articular posiciones; de los diferentes modos y mecanismos de intervención; de los 
desniveles en la distribución de recursos materiales y simbólicos entre el $<$ pueblo> (Monedero, 2017, p. 104).

El Estado, siguiendo este principio, posee inclinaciones a que ocurran determinadas cosas y no otras y es en ese sentido en el que a ciertos sectores le es más fácil acceder al aparato del Estado en vez de a otros. Pensando en términos de representatividad y tomas de decisión a nivel ejecutivo, eporque cuesta tanto que sectores afro-descendientes, indígenas u obreros lleguen al poder? En América Latina contamos con apenas los sendos casos de Evo Morales en Bolivia y Luiz Inácio Lula Da Silva en Brasil, quizás estos ejemplos sirvan para pensar un tipo de política más inclusiva y plural en donde los orígenes o los rasgos no sean un factor que determine alguna instancia.

Sostenemos que la noción de "selectividad estratégica" por parte de los Estados es un claro ejemplo de lo que anteriormente se planteó como subalternidad política ya que es muy claro cómo muestra la facilidad o dificultad que tienen los distintos sectores de una sociedad a la hora de obtener derechos y/o oportunidades en base a su origen, raza, etnia o clase. ¿Por qué es necesario que esas personas ligadxs a los sectores más postergados lleguen al gobierno? ¿A quién le conviene y a quién no? El Estado es un territorio de disputa, donde se ponen en juego distintos intereses, porque según quien o quienes predominen en el mismo, se pueden llegar a dar determinadas políticas públicas para contrarrestar el racismo y la discriminación; o bien puede pasar todo lo contrario, que se normalicen dichas prácticas desde las instituciones u otros órganos de la misma índole.

Sin embargo, sostenemos que, según los determinados procesos políticos que se lleven adelante, la subalternidad se puede tornar variable. Está claro que no es lo mismo un Estado que promueva modelos generales que priven los accesos a una vida digna a sus propios habitantes:

A pesar de ser mayoría en un país de más de 200 millones de habitantes, la población negra enfrenta otras barreras: está menos escolarizada, tiene más dificultades a la hora de conseguir un empleo y recibe salarios más bajos que los de los blancos, incluso cuando poseen el mismo grado de escolaridad (Santandreu, 2017).

Que un Estado que integre y acompañe a su población como en el caso de la Ley Antirracista promulgada por el gobierno boliviano en el año 2010, la cual buscaba eliminar todas aquellas expresiones que vulneren la dignidad de indígenas, campesinxs y pobres desde los medios de comunicación o la creación de la Unidad Fiscal Especializada en violencia contra las Mujeres (UFEM) en Argentina, la cual no sólo se encargaba de recibir denuncias y realizar investigaciones, sino que también diseña políticas públicas y estrategias de prevención frente al fenómeno de la 
violencia de género. De aquí la siguiente conclusión: el Estado es un gran catalizador de derechos, pero así como los brinda también los puede privar. La palanca que hace inclinar al Estado de un lado o del otro es la voluntad política.

\section{Racismo y actualidad}

Hasta aquí hemos desarrollado cuestiones referidas al recorrido histórico del racismo en nuestra región y factores que contribuyen a la continuación de estas prácticas; ello tuvo por objeto contextualizar la realidad latinoamericana respecto de los tratos discriminatorios que -a pesar de ser condenados por los Tratados Internacionales de Derechos Humanos- se siguen replicando diariamente.

En esta sección haremos referencia a determinados grupos de personas que se encuentran en una posición de vulnerabilidad y discriminación, y que, en razón de esto, corresponde garantizar ciertas protecciones especiales por parte de los Estados a los fines de que se respete de manera efectiva su derecho a la igualdad y no discriminación; tales grupos son: niños, niñas y adolescentes, personas inmigrantes, grupos indígenas, mujeres, entre otros.

Más de quinientos años de colonialismo han sido suficientes -y demasiadospara que se sigan naturalizando prácticas discriminatorias que han tenido su punto de partida en aquel primer encuentro con "el otrx" y para que el Estado haga oídos sordos a las situaciones similares producidas -incluso- por sus propias instituciones. "En Latinoamérica y el Caribe, el racismo y la discriminación tienen características históricas, económicas, sociales y culturales, que han mantenido a grupos específicos, entre estos los pueblos indígenas, afrodescendientes y mujeres, en condiciones de marginalidad, exclusión y pobreza extrema" (Cuéllar). No solo es consecuencia del factor colonialista, sino que, como hemos referido anteriormente, el racismo y la discriminación sirven para profundizar las jerarquías raciales de las que el capitalismo se beneficia.

El capitalismo, en tanto sistema, establece en su lógica que todo es posible de adquirir en tanto sea posible mercantilizarlo (hoy en día desde productos básicos hasta educación), para que su fórmula surta efecto es necesario que lxs sujetos ingresen a esa curiosa instancia topográfica llamada mercado, quien no cumpla con los requisitos necesarios para establecerse en la lógica capital/mercantil (sea por lo que fuere) está condenado a la expulsión y a la exclusión. El capital, necesariamente, necesita excluir para funcionar.

El sistema mundo resultante, esa mezcla de Estados nacionales, modelo capitalista y manera de pensar que llamamos modernidad, se iba a organizar de manera tal que necesitaba grandes grupos de población 
malviviendo para que unas minorías gozarán privilegiadamente de la vida social (Monedero, 2017, pp. 182-183).

Retomando la cuestión planteada anteriormente, el colonialismo interno también juega de las suyas. Constantemente busca catalogar a dirigentes populares como inferiores, porque son apoyados por una parte de la población que consideran débiles mentales, jerárquicamente menos que ellos. "El colonialismo siempre es producto de un esquema hegemónico mundial, que opera tanto en el centro del poder colonizador como en la periferia colonizada" (Zaffaroni, 2015, p. 47). Así como a lo largo de la historia el colonialismo ha operado de diferentes maneras -desde la ocupación territorial, hasta valerse de las deterioradas oligarquías locales- su accionar en la actualidad no escapa a una estrategia orquestada tanto desde afuera como desde adentro. Hoy, su herramienta por excelencia es el Lawfare.

¿En qué afecta este fenómeno al racismo en la actualidad? Como ha pasado desde el comienzo de la historia reciente en nuestra región, al imponerse -sea por el medio que fuera- ciertos gobiernos (mayormente antipopulares), o que simplemente son ajenos al bienestar de su pueblo, se instrumentan medidas que afectan profundamente a la población engendrando una nueva evolución a prácticas racistas que ya deberíamos haber dejado atrás hace mucho tiempo.

Con el advenimiento de gobiernos antipopulares -sea en la época que sea, y de la forma en que logren imponerse- podemos distinguir determinadas políticas orientadas a reproducir determinados sentimientos tanto de superioridad como de inferioridad, los cuales afectan directamente a la replicación de prácticas racistas y discriminatorias.

A modo de ejemplo, cuando se establecen en el gobierno, se llevan adelante políticas de exclusión social como efecto colateral de su insaciable apetito de aprovecharse de su situación institucional para favorecer intereses particulares. Frente a las grandes crisis económicas alimentadas por estos gobiernos, se agudiza un discurso -impulsado muchas veces por los mismos miembros de sus grupos políticosque tiene como principal culpable de todos los males del país a los grupos de inmigrantes. "Es justamente en esas crisis recesivas cuando se exacerban manifestaciones xenófobas adjudicadoras a los inmigrantes del aumento de la desocupación y de la delincuencia” (Grimson, 2006, p. 8).

El discurso xenófobo impulsado por los mismos, muchas veces se utiliza para mitigar los daños ocasionados por ellos mismos, derivando en abusos policiales contra dichos sectores, situaciones de odio social, pérdida de empleos o, incluso, deportaciones injustas. Entendemos a la xenofobia y al racismo como dos fenómenos que guardan una estrecha relación entre sí, en tanto ambos refieren a la negación o al rechazo de una o más personas por el simple hecho de ser diferentes a lo que ellxs 
consideran dentro de la categoría de lo "normal" o incluso, en términos morales, lo que está "bien."

En América Latina y el Caribe la xenofobia hunde sus raíces históricas en la discriminación étnico-racial. El imaginario cultural de negación del otro se transfiere más tarde al otro-extranjero, sobre todo si no es blanco y migra desde países caracterizados por una mayor densidad de población indígena, afrolatina o afrocaribeña (Bello, 2001, p. 43).

"Ellxs" nos sacan el trabajo. "Ellxs" estudian en nuestras universidades. "Ellxs" utilizan nuestro sistema de salud. "Ellxs" es un calificativo recurrente, un justificante absurdo para las nefastas políticas de vaciamiento llevadas adelante por estos operadores foráneos;

la mayor afluencia de migrantes internacionales y fronterizos generan -o reviven- la xenofobia y los prejuicios raciales en los países receptores, lo cual se exacerba si en estos últimos aumenta el desempleo y se hacen más deficitarios los servicios sociales básicos provistos por el Estado (Bello, 2001, p. 42).

No es una nueva estrategia, y los inmigrantes no son los únicos grupos que sufren las consecuencias de los discursos de odio instaurados socialmente. Los grupos marginados por factores económicos también sufren estas prácticas discriminatorias, ya que siempre son "ellxs", y nunca son "nosotrxs".

Por poner un ejemplo, es recordado los comentarios de un excandidato a vicepresidente en la Argentina que alguna vez advirtió que "con este tema del refugio también nos comimos todos los migrantes senegaleses que hacen venta clandestina e ilegal en el Once" refiriéndose a los vendedores ambulantes de la ciudad de Buenos Aires $^{3}$. También podríamos mencionar el Decreto 70/2017, emitido por el gobierno de turno en el período 2015-2019, el cual había endurecido la política migratoria a los fines de complicar el ingreso al país y de facilitar la expulsión ampliando como impedimento para el ingreso y permanencia en el país contar con antecedentes de cualquier delito cuya pena fuera privativa de libertad, pudiendo de este modo, expulsar inmediatamente a lxs extranjerxs en esa situación, vulnerando el derecho a la defensa, de contar con asistencia legal y sin tener en cuenta la realidad de los migrantes, sus lazos con el país, sus contextos familiares:

Un caso emblemático fue el de Vanessa Gómez Cueva, una mujer peruana residente en Argentina, que había cumplido una condena a 4 años de prisión en un juicio abreviado por violación a la ley de drogas. Estudió

\footnotetext{
3 Página 12 (14/01/2020) "Pichetto desplegó todo su arsenal de violencia y xenofobia". Recuperado de: https://www.pagina12.com.ar/241517-pichetto-desplego-todo-su-arsenal-de-violencia-y-xenofobia.
} 
enfermería y rearmó su vida, pero cuando hacía trámites para actualizar sus documentos, se detectó su antecedente (Hauser, 2021).

Como consecuencia de esto, fue deportada

sin aviso, la separaron de sus hijes de 6 y 14 años por entonces, y la subieron a un avión con su otro hijo de 2 años. El escándalo internacional fue de tal magnitud que la Dirección de Migraciones tuvo que volver sobre sus pasos y permitir el regreso de Vanesa (Hauser, 2021).

Pero no todas las personas en esta situación tuvieron la misma suerte. No podemos precisar cuántas familias han pasado por esto, siendo expulsadas sin considerar su condición socio-económica y de arraigo con el país. Vulnerando y acometiendo sobre sus derechos más fundamentales.

\section{3. ¿Y si llegan los gobiernos populares?}

Hemos referido varias veces a determinados factores que favorecen las prácticas racistas, uno de los que quizás ha tomado más fuerza, es el colonialismo, quien ha elegido como enemigo a los gobiernos populares de la región.

¿Qué pasa con el racismo y las prácticas discriminatorias cuando un gobierno "populista" llega al poder? Para ello, vamos a tomar como referencia los gobiernos populares que tuvieron lugar en Argentina en el período 2003-2015.

"Frente a un proceso de negación histórica y sostenida, el Estado argentino inició en la última década la incorporación del concepto de racismo en su política institucional" (Maluf, 2017, p. 165). Concebimos al mismo como un eje fundamental en la lucha contra el racismo, ya que no podemos combatir aquello que no conocemos. En primera instancia, los Estados deben reconocer el problema -dejar de negarlo-, luego generar políticas de investigación, capacitación, reparación, saneamiento y no repetición.

En el año 2005 se aprobó en Argentina el documento Hacia un Plan Nacional contra la Discriminación como consecuencia directa de la Conferencia de Durban. El documento presentaba un Diagnóstico y Propuestas. Se trató de un hito histórico ya que Argentina junto a Suecia y Noruega habían sido los países vanguardistas en cumplir con los compromisos de aquella Conferencia Mundial (Instituto Nacional contra la Discriminación, la Xenofobia y el Racismo [INADI])

De dicho documento se desprendieron cerca de 250 propuestas estructuradas en distintos ámbitos, que necesariamente debieron ser un eje fundamental para comenzar a estructurar políticas públicas destinadas a limitar las prácticas racistas. Si bien algunas han podido realizarse, la realidad es que no todas pudieron ser atendidas. A los fines de orientar al lector/a el sentido de las propuestas que -creemos- son y 
fueron necesarias para plasmar una directiva institucional contra el racismo, hemos destacado las siguientes:

- Propender a cambios estructurales que impliquen una sustancial redistribución del ingreso y el desarrollo económico inclusivo, a fin de lograr la superación de la situación de pobreza de la mayoría de la población del país y su correlato en términos de discriminación.

- Garantizar en el orden nacional el derecho de asociación que les cabe a todas las organizaciones nucleadas alrededor de la defensa y promoción de los derechos de las personas con diferente orientación sexual o identidad de género.

- Incrementar el grado de profesionalidad y formación requeridos a los efectivos policiales en todas las provincias, incorporando a la capacitación la formación en Derechos Humanos y haciendo énfasis en temas de nodiscriminación.

- Arbitrar los medios para capacitar y actualizar los contenidos de la formación de jueces, operadores de justicia y funcionarios públicos sobre el desarrollo de la normativa y compromisos internacionales de nuestro país en materia de Derechos Humanos y comprensión de los mecanismos de la discriminación en todas las esferas.

- Promover la sanción de una ley que restituya a los pueblos indígenas sus lugares sagrados, garantizando su participación en el proceso.

- Promover la sanción de una ley que declara el agua, la energía eléctrica y el gas como bienes sociales que deben ser garantizados a toda la población como condición mínima de vida digna e igualitaria.

- Promover, desarrollar y subvencionar proyectos de investigación por parte de los órganos estatales pertinentes (INADI, INDEC, Secretaría de DD. HH, Universidades Nacionales) a fin de mensurar la dimensión del problema discriminatorio, analizando los discursos mediáticos y educativos, las conductas discriminatorias, sus orígenes y casualidad, así como los modos de desarticularlas.

- Adoptar medidas tendientes a que los medios de radiodifusión estatales garanticen la diversidad cultural, lingüística, sectorial y regional.

Dentro de esta selección de propuestas que hemos hecho, extraídas del documento antes mencionado, queremos destacar aquellas políticas destinadas a la investigación igualitaria por distintas instituciones, ya que consideramos que desde la academia el camino hacia la no-discriminación debe también ser una política bien determinada. Por otro lado, garantizar el derecho de asociación de los distintos grupos de defensores y defensoras de Derechos Humanos en materia de racismos y 
no-discriminación, es fundamental ya que, como sostuvo la Corte IDH en el caso Escaleras Mejía y otros Vs. Honduras: “...la prevalencia de los derechos humanos en un estado democrático, se sustenta en gran medida, en el respeto y la libertad que se brinda a las personas defensoras de derechos humanos en sus labores...”.

Lo que quisimos manifestar con estos ejemplos, es que existen formas de llevar adelante una política institucional destinada a limitar al racismo, para ello, el primer paso es dejar de negar que existen estas prácticas, poner en discusión estos temas, establecer un diálogo serio con los afectados. Institucionalizar las estrategias contra el racismo es el primer paso para luego impulsar proyectos políticos que busquen limitar cualquier tipo de práctica discriminatoria, lograr igualdad y garantizar la no replicación.

\section{Conclusiones}

Sabemos que el racismo es un fenómeno que resulta totalmente anclado en nuestra cultura. Si hace algunos siglos el discurso racista era argüido desde el cientificismo, hoy el racismo está presente en un campo mucho menos especializado, pero mucho más complejo: el sentido común. Desconocemos si esperar por una sociedad en donde no existan ni las prácticas ni los discursos del odio racial sea utopista, lo que sí creemos es que se pueden prevenir, se pueden articular medidas o contradiscursos para que, por lo menos, cualquier manifestación racista no quede impune, tomando un poco prestada y alterando aquella frase de Buenaventura Durruti "al racismo no se le discute...".

La salida debe ser apostar por un renovado cambio cultural en sentido amplio, un complejo que nos haga repensar y reelaborar buena parte de nuestras prácticas, sentidos de creencias y de valores. $\mathrm{Y}$, por supuesto, la herramienta que creemos mejor para establecer dicho cambio de paradigma es la política.

Para ello debemos esperar (y exigir) que haya una sincronización desde los tres poderes del Estado para que no se toleren las instancias de odio, desde la creación e implementación de políticas públicas que amparen a las víctimas hasta una justicia que penalice toda apología racial. Con esto que no se entienda que esperamos un efecto de "derrame" del ethos antirracista desde la casta política o cúpula dirigencial hacia al resto de la población, sino que pensamos en una relación dialéctica entre ciudadanía (incluidos también agentes como los sindicatos o los movimientos sociales) y funcionarixs públicos, la tarea compete a todos y todas desde su lugar. Para lograr una verdadera transformación social positiva para reducir en la mayor medida posible las prácticas racistas y discriminatorias que puedan darse en cualquier ámbito, es necesario que todos los sectores sociales y estatales tomen cartas en el asunto; podríamos poner como ejemplo el impacto que ha tenido la "Ley Micaela" desde su 
sanción en el año 2019. La misma establece la capacitación obligatoria en género y violencia de género para todas las personas que se desempeñan en la función pública; a través de los procesos de formación integral, se busca la adquisición de herramientas que permitan identificar las desigualdades de género y elaborar estrategias para su erradicación. Se busca transmitir herramientas y (de)construir sentidos comunes, que cuestionen la igualdad y la discriminación.

A modo de ejemplo, la Ley Micaela sin dudas forma parte de una política de estado que busca desalentar la discriminación por razones de género y, a su vez, reducir la violencia mediante la capacitación de lxs agentes del Estado. La misma se extendió a otros sectores como, por ejemplo, clubes y entidades deportivas de la provincia de Buenos Aires. También se ha propuesto en la ciudad de Rosario que se instrumenten dichas capacitaciones para taxistas, remiseros y colectiveros. Sin dudas, este tipo de capacitaciones deberían llegar a la mayor parte posible de la población, a eso nos referimos cuando sostenemos que los grandes cambios se logran entre todxs. Abordar y capacitar sobre la violencia y la discriminación -en este caso de género- es una de las formas de comenzar a cambiar las cosas.

$\mathrm{Si}$ bien en páginas anteriores atendimos las incumbencias que ha tenido la práctica racista, creemos que es el Estado el gran amplificador de los posibles cambios sociales, en ese sentido, si la entrada hacia el racismo se dio en una parte por el Estado, la salida es también mediante él. Hemos intentado ver el doble rostro que puede tener el Estado ante este tipo de fenómenos, sus luces y sus sombras, su potencia está demostrada. Hoy en día, y viendo los casos que han ocurrido ahora ya en todo el mundo, la formación de un Estado que desarticule las prácticas racistas resulta imperiosa, América Latina necesita recobrar el camino que alguna vez intentó, con aciertos y errores, para establecer un nuevo paradigma cultural.

Cualquier tipo de práctica discriminatoria, desde reproducir estereotipos hasta cualquier acto de hostigamiento, maltrato o segregación, en el ámbito que sea, produce una vulneración en los derechos de estas personas. Son derechos negados, porque no pueden ejercerlos como consecuencia del racismo que padecen, sea su libertad de circular libremente, su honor, su integridad física, su derecho a trabajar, o cualquier otro. A lo largo de este trabajo hemos mencionado y relacionado algunos factores que consideramos que han sido fundamentales tanto en el surgimiento de estas prácticas, como así también, su influencia en la ejecución y reiteración de estas prácticas: el colonialismo, los beneficios para el capitalismo de que exista una escala de jerarquía racial, los efectos de la globalización actual al reiterar constantemente un nuevo encuentro con lx otrx o los efectos de la subalternización. Factores que sirven a la conformación de un "racismo estructural", considerando al mismo como 
todos los factores, valores y prácticas que colaboran con la reproducción de la asociación estadística significativa entre raza y clase (definida aquí como la combinación de situación económica e inserción profesional), es decir, todo lo que contribuye para la fijación de las personas no-blancas en las posiciones de menor prestigio y autoridad, y en las profesiones menos remuneradas (Segato, 2012, p. 5).

A su vez, en este breve ensayo hemos podido ejemplificar algunas medidas llevadas a cabo por gobiernos populares para hacer frente al racismo. Observamos medidas tendientes a abordar la problemática de la violencia de género; y medidas tendientes a limitar el racismo estructural en medios de comunicación. Todos esos derechos negados, pueden abordarse, pueden comenzar a solucionarse; como así también se pueden profundizar. Como también hicimos referencia, para lograr cambios positivos, requerimos avanzar hacia una dinámica social que incumba no sólo a los gobiernos de turno, la tarea no es solo allí, la realidad es que también deben soplar aires de una mayor responsabilidad ciudadana, mucho más precisa para que se puedan advertir los casos de racismo incluso en instancias de cotidianeidad.

Reconocer en nosotrxs mismxs y en nuestros ambientes más íntimos, como la familia o amistades, discursos o gestos de odio es un buen primer paso para empezar a cambiar las cosas. El trabajo no es fácil, el racismo en tanto constructo imaginario lleva siglos de ventaja. Pero, una vez más, creemos que solo una gran cohesión de los distintos agentes sociales pasando también por todos los órganos institucionales es la fuerza que se necesita para lograr que este fenómeno no tenga asidero.

\section{Referencias bibliográficas}

Bambirra, V. (1975). Sobre el nacionalismo en América Latina. El Comité Editorial. México. Recuperado de: https://www.probdes.iiec.unam.mx/index.php/pde/article/download/4149 9/37726/105297.

Bello, A. y Hopenhayn, M. (2001). Discriminación étnico-racial y xenofobia en América Latina y el caribe. Publicación de las Naciones Unidas. Santiago de Chile. Recuperado de: https://repositorio.cepal.org/bitstream/handle/11362/5987/1/S01050412_e s.pdf.

Beverley (2010). Subalternidad/Modernidad/Multiculturalismo. Revista Científica de Información $y \quad$ Comunicación. Recuperado de https://idus.us.es/bitstream/handle/11441/18300/file_1.pdf.

Borges, R. El racismo es un dínamo del capitalismo. Recuperado de https://www.goethe.de/ins/ar/es/kul/fok/hum/21249390.html. 
Castro Gómez y Mendieta. (1998). Teorías sin disciplina (latinoamericanismo. poscolonialidad y globalización en debate). Edición de los propios autores.

Cuéllar, R. Pobreza y Derechos Humanos: reflexiones sobre el racismo y la discriminación. Crónica ONU. Recuperado de: https://www.un.org/es/chronicle/article/pobreza-y-derechos-humanosreflexiones-sobre-el-racismo-y-la-discriminacion.

González Casanova, P. (2006). Sociología de la explotación. Editorial CLACSO. Buenos Aires.

Grimsom, A. (2006). Nuevas xenofobias, nuevas politicas étnicas en Argentina. Recuperado de: https://ccp.ucr.ac.cr/noticias/migraif/pdf/grimson.pdf.

Hauser, I. (2021). El gobierno derogó el decreto migratorio del macrismo. Página 12. Recuperado de: https://www.pagina12.com.ar/327647-el-gobierno-derogoel-decreto-migratorio-del-macrismo.

INADI. Nuevo Plan contra la Discriminación. Instituto Nacional contra la Discriminación, la Xenofobia y el Racismo. Recuperado de https://www.argentina.gob.ar/inadi/nuevo-plan-nacional.

Kosikowski, Z. (2013). Finanzas internacionales. Tercera edición, editorial Mc Graw Hill Education. México.

Maluf, N. A. y Vélez, R. F. Después de la negación: el Estado argentino frente al racismo y la discriminación. Cuadernos del CENDES dossier: Argentina durante la postconvertibilidad año 34. No 95. Tercera época, mayo-agosto 2017, Caracas, Venezuela.

Moldiz, H. (2020). Golpe de Estado en Bolivia, la soledad de Evo Morales. Editorial Ocean Sur. Bolivia.

Monedero, J.C. (2017). Los nuevos disfraces del Leviatán: el Estado en la era de la hegemonía neoliberal. Editorial Akal S.A. Argentina.

Pichetto desplegó todo su arsenal de violencia y xenofobia. (14/01/2020). Página 12. Recuperado de: https://www.pagina12.com.ar/241517-pichetto-desplegotodo-su-arsenal-de-violencia-y-xenofobia.

Pombo, M. D. P (1999). "Racismo y nacionalismo: la construcción de identidades excluyentes." Revista Politica y Cultura, núm. 12. Recuperado de: https://www.redalyc.org/articulo.oa?id=26701204

Quijano, A. (2011). ¡Qué tal raza! Publicado en América Latina en Movimiento, No. 320. Recuperado de: http://alainet.org/publica/320.phtml

Rueda E. y Villavicencio S. (Eds.) (2018). Modernidad, colonialismo y emancipación en América Latina. Editorial CLACSO. Buenos Aires.

Santandreu, A. (2017). La comunidad negra en Brasil, la que más sufre pese a ser mayoría. La Vanguardia. Recuperado de: 
https://www.lavanguardia.com/internacional/20171120/433044093345/co munidad-negra-brasil-sufre-racismo-desigualdad.html.

Segato, R. (2012). Racismo, discriminación y acciones afirmativas: herramientas conceptuales. Observatorio da Jurisdição Constitucional. Brasília: IDP, Ano 5, 2011/2012. ISSN 1982-4564.

Serra, A.M. (2017). Esterilizaciones (forzadas) en Perú: Poder y configuraciones narrativas. Revista de Antropología Iberoamericana, vol. 12, núm.1. Recuperado de: http://www.aibr.org/antropologia/netesp/numeros/1201/120103.pdf.

Stavenhagen, R. (1993). Racismo y xenofobia en tiempos de globalización. Estudios Sociológicos XII: $\quad 34$. Recuperado de https://estudiossociologicos.colmex.mx/index.php/es/article/download/994 /994/.

Torres Guillén, J. (2017). El concepto de colonialismo interno. Recuperado de http://conceptos.sociales.unam.mx/conceptos_final/641 trabajo.pdf.

Zaffaroni, E. R. (2015). El derecho Latinamericano en la fase superior del colonialismo. Editorial Madres de plaza de mayo. Buenos Aires. 